\title{
Attitude, Knowledge, and Use of Self-Medication with Antibiotics by Outpatients of Gbagada General Hospital Gbagada Lagos.
}

\author{
Odis Adaora Isabella \\ School of Public Health, Texila American University, Guyana
}

\begin{abstract}
Self-medication with antibiotics is a threat to global health and becoming increasingly common due to multiple factors. The aim of our study was to evaluate the attitudes, knowledge, and use of selfmedication with antibiotics among outpatients of Gbagada General Hospital Gbagada - Lagos, Nigeria. The objective of this research was to access the attitudes, knowledge and use among the Patients that use Self-medication with antibiotics. The study design was a cross-sectional descriptive study. A pretest of a closed-ended questionnaire was distributed to the respondents, corrections were made, and data was collected in February 2021. 402 Outpatients of the Gbagada General Hospital Gbagada city area of Lagos was recruited for the study in the aforementioned time period through multi-stage probability sampling. Thirty-three percent of respondents said antibiotics could cure all infections. Forty-eight percent of respondents said antibiotics might be effective even if they don't complete their dosage. $94.78 \%$ of our respondents have taken antibiotics, and $71.89 \%$ have selfmedicated with antibiotics. Forty-eight percent of respondents said antibiotics might be effective even if they don't complete their dosage, Not completing the dosage (49.25\%), Using antibiotics repeatedly (43.28\%), and Self - medication (34.08\%). The percentage of the respondent that have taken antibiotics once and twice between March 2020 and February 2021, which was during the COVID 19 First and second wave in Nigeria, were (36.07\%) and (25.87\%) respectively. We recommend the use of media to discourage the masses from self-medication with antibiotics.
\end{abstract}

Keywords: Antimicrobial resistance, Antibiotics, Self-medication.

\section{Introduction}

Self-medication with antibiotics is a threat to global health and becoming increasingly common due to multiple factors. Selfmedication as defined by WHO is the utilization of drugs to treat self-diagnosed disorders or symptoms, or the irregular or continuous use of a prescribed drug for chronic or repeated diseases or symptoms without Doctor's description [1].

The absence of clinical assessment of the condition by a qualified medical doctor is a result to self-medication, which could result in overlooked diagnosis and hindrances in appropriate treatments [2]. The research discovered that the Chemotherapy of bacterial infections depends on the isolation of the aberrant agent, categorization of the agent's antibiotic susceptibility, and bringing the suitable antibiotic to the site of infection in adequate quantities to either kill the bacteria (bactericidal) or modify it to allow the body's immune response to drug and eventually kill it [3]. Previous researchers defined selfmedication defined as "taking of drugs, herbs or home remedies on one's own initiative, or on the advice of another person, without consulting a doctor" [4]. This procedure includes the use of medication by oneself or giving it to family members, friends, colleagues, including children or the elderly [5]. Previous literature revealed that the prevalence of self-medication is comparatively greater in 
developing countries as compared to developed countries $[6,7]$. The researchers also found out that regions of Eastern and Southern Europe had comparatively higher rates of selfmedication than northern and western areas of Europe [7].

The prevalence was 3\% in northern Europe [7]. An increase in self-medication practices has also been observed in Latin America [8]. While there is a huge increase in Asia, with the values being reported to be around $4-75 \%$ [9]. A previous study carried out in Karachi discovered that the self-medication rate in university students was $80.4 \%$ and that in the urban population was $68.1 \%[10,11]$.

Two decades ago, the World Health Organization (WHO) encouraged the use of self-medication without medical council in order to prevent and treat diseases in a faster and more efficient manner and also to reduce the load on healthcare centers in the rural areas $[12,13]$. The recent WHO reports on antimicrobial resistance states that it is a current global health threat [1]. It has been discovered that the use of medicines has led to problems in the short and long term. Self-medication is becoming increasingly common due to multiple factors. With information easily accessed through the internet, people are exposed to a greater amount of information, and they want to make independent decisions regarding their lives, which includes medications too [14]. Another important reason is the increased access to antibiotics in countries like Nigeria, where they are sold without a prescription, giving people a chance to ignore the Doctor and use their own opinion or the advice of others to self-medicate [15-18]. The causes of increased use of self-medication with antibiotics are because of an attitude of medical/health care providers, financial problems, illiteracy, inadequate healthcare facilities, or even a lack of time [12]. Studies carried out in Argentina, Brazil, Chile, Colombia, Costa Rica, and Nicaragua linked the high self-medication rates to a lack of access to healthcare facilities [8].
Another interesting discovering in Honduras was that self-medication was connected to urban dwellers. However, no association was built with socio-economic status [19].

Individuals indulging in the act of using antibiotics do not have adequate information regarding their proper use, dosage, and any side effects $[20,21]$. Abuse of such drugs may cause harm to the patients. There is a perception amongst the masses that common respiratory infections can be cured by antibiotics [22]. This has led to increased uninstructed use of antibiotics that has resulted in many pathogens becoming resistant to them. Strains of $S$. pneumonia, S. Typhi, Neisseria gonorrhoeae, and Shigella species have been found that are now resistant to common antibiotics [23-26]. [27] also found a direct relationship between inappropriate drug use and antibiotic resistance. In Pakistan, pharmacies are under a legal requirement to sell specific drugs only on prescription from a registered medical professional [28, 29]. However, the adherence to the law by these pharmacies is not encouraging, resulting to the high rates of selfmedication [28, 30]. In Lome, Togo, pharmacies do not sell any drug without Doctor's prescription.

In the research conducted in Nigeria by [31] out of the 1230 respondents from undergraduate students and community members, prescription of antibiotics by a physician was $33 \%$ and $57 \%$, respectively, amongst undergraduate students and community members. The researchers tested the respondent's knowledge of antibiotic resistance (ABR) and found that undergraduate students displayed less knowledge that selfmedication could lead to ABR $(32.6 \%$ and $42.2 \%$, respectively).

The study also discovered that selfmedication with antibiotics is highly prevalent in Northwest Nigeria, with most medicines being purchased from un-licensed stores without a prescription from a physician. This is very rampant in Nigeria as Pharmacies have no regulation or restriction of the sale of drugs. 
[31] also observed a significant gap in respondents' knowledge of ABR.

\section{Research Questions for this Study}

Does the individuals indulging in the act of using antibiotics do not have adequate information regarding their proper use, dosage, and any side effects. What are the multiple factors that lead to or result to increase of Self medication with antibiotics?

\section{Assumptions}

The assumption in this study is that there is the probability of self-medication with antibiotics, the effectiveness of antibiotics, lack of knowledge, and cost that leads to increased self-medication with antibiotics.

However, due to the high economic cost of hospital care, lack of time to visit the hospital, and often personal beliefs, and the fear of going to the hospital after-effects like contracting diseases like COVID - 19, people usually regard Doctor's clinical assessment and prescription as a voluntary rather than compulsive measure.

\section{Hypothesis}

Lack of knowledge of awareness of antibiotics resistance and high cost gives rise to Self - medication with antibiotics, and there may be other multiple factors or significant determinants that are difficult to measure and quantify, which determine causes of Self medication with antibiotics.

\section{Aim}

The aim of our study was to evaluate the attitudes, knowledge, and use of selfmedication with antibiotics among outpatients of Gbagada General Hospital Gbagada - Lagos, Nigeria.

\section{Specific Objectives}

a) To examine the level of knowledge and use of antibiotics among outpatients of Gbagada General Hospital Gbagada Lagos b) To find out the frequency and reasons of Self - medication with antibiotics among outpatients of Gbagada General Hospital Gbagada - Lagos

c) To assess the adverse effects in the outpatients that use Self - medication with antibiotics

d) To examine the association of sociocultural factors with antibiotics use.

\section{Literature Review}

According to [32], 39.3\% had practiced Selfmedication with antibiotics (SMA). The main reason for taking antibiotics is for runny nose, nasal congestion, cough, sore throat, fever, aches and pains, vomiting, diarrhea, and skin wounds. There was no significant difference between the medical or non-medical students regarding whether they had ever taken antibiotics $(p=0.082)$, but a significantly higher percentage of non-medical students had selfmedicated with antibiotics compared to medical students $(p<0.001)$. Responses from another research conducted by [31] discovered that the undergraduate students identified that the commonly self-diagnosed illnesses treated with antibiotics were malaria (14.5\%), typhoid (13.1\%), stomach pains (12.7\%), diarrhea $(11.9 \%)$, cold $(0.8 \%)$, ear and throat pain (1.2\%), asthma (1.6\%), sinusitis (2.2\%), dental caries $(2.8 \%)$, and fever $(3.9 \%)$. On the other hand, the community members were more likely to use antibiotics for illnesses such as dysentery (19\%), infection (17\%), typhoid $(13 \%)$, sinusitis $(1.8 \%)$, asthma (2.2\%), food poisoning $(3.1 \%)$, and ear and throat pain (3.2\%) [31]. Another research discovered that Antibiotics were used to treat self-perceived sore throat, fever, pain, cough, vaginal discharge, eye problems, common influenza, urinary infections, respiratory tract infections, wounds, and toothaches [33].

The frequency of SMA taken by medical students have significantly lower than the nonmedical students with a Chi-square of $p<0.001$ the significant differences regarding reasons for 
SMA between medical and non-medical students [31]. The research [31] discovered that the frequency of antibiotic used among undergraduate students and community members were reported as $43 \%$ and $26 \%$ weekly, respectively. Undergraduate students were more likely to use antibiotics as reported in the weekly usage of antibiotics (43\%) compared to community members $(26 \%)$.

Another research found out that antibiotics were purchased by referring to the scientific or generic name, which was one of the most common patterns of SMA used by the participants from the middle and high socioeconomic pharmacies. The names of antibiotics were known by the participants since most indicated previous use of, prescribed by a health care professional (HCP) when they had sought help at the hospital or clinic. The researchers discovered that participants who requested an antibiotic using a previous prescription pattern named amoxicillin with clavulanic acid, azithromycin, and cotrimoxazole as the most purchased NPA. They also found out that the participants did not know precisely the uses and adverse effects of the requested antibiotics; they believed that the antibiotics were useful in treating certain diseases in 2 to 3 days. [34].

In the research [34], the majority of the pharmacy clients interviewed, 30 (93.75\%) admitted frequent use of Non prescribed antibiotics (NPAs), 15 (88.2\%) out of the 17 pharmacists interviewed admitted dispensing NPAs [34]. While the majority of the participants (16) mentioned the use of amoxicillin, also known as 'two colours medicine', 14 participants mentioned the use of cotrimoxazole, and seven mentioned amoxicillin with clavulanic acid. Two to five participants also used tetracycline, ciprofloxacin, azithromycin, doxycycline, erythromycin, metronidazole, and phenoxymethylpenicillin [34]. The researchers questioned the manner customers request NPA, pharmacists unanimously admitted that SMA is a frequent practice among customers. Another pharmacist admitted SMA is a widespread and rampant practice and that most customers seem to be very well informed [34]. [31] also discovered that the distribution pattern of most commonly used antibiotics among undergraduate students were metronidazole (18\%), amoxicillin/clavulanic acid (16.8\%), ampicillin/cloxacillin (14.8\%), cotrimoxazole (12\%), and tetracycline (11\%). Meanwhile, the community members reported the highest use of ampicillin/cloxacillin (23.5\%), ciprofloxacin (18.7\%), ampicillin (12.5\%), tetracycline $(11.4 \%)$, and amoxicillin/clavulanic acid (10.6\%). \%).

[32] found out that most practiced SMA because of its Convenience (42.3\%) [Medical $(41.7 \%)$ and non-medical students $(42.5 \%)]$ or cost savings [Medical (37.5\%) and non-medical students (35.2\%), though not much difference, were seen between both groups. Differences were found relating to lack of trust in the prescribing doctors as one of the reasons for SMA, where none of the medical students had a lack of trust in their prescribing doctors as compared to non-medical students (8.9\%). Furthermore, more non-medical students gave "other reasons" as their reason $(9.5 \%)$, while more medical students gave multiple answers to these questions (16.7\%). However, there was no significant difference between the medical and non-medical students regarding the diseases, the basis for SMA, nor the reasons they stopped antibiotics during SMA ( $p=0.052$, 0.428 , and 0.684 , respectively). The common disease or condition for SMA was due to fever (25.5\%); SMA was mainly practiced based on a previous doctor's prescription (35.9\%), and the majority stopped the antibiotics once their symptoms disappeared (31.2\%). No medical students stated a lack of trust in prescribing doctors, whereas (8.9\%) non-medical students stated that was a reason for SMA (Chi-square $p=0.005$ ).

[32] found out that the main decision for choosing amoxicillin during SMA as the type 
of antibiotics (37.1\%); obtaining their antibiotics from community pharmacies was $(66.0 \%)$; knowing the dosage after consulting a doctor was (27.8\%) and taking only one type of antibiotic during an illness was (55.1\%). Haque discovered that, there was no significant difference between medical and non-medical students regarding the dosage and the maximum number of antibiotics taken during an illness. However, significant differences were observed between the two groups regarding the consideration for SMA and where they obtained the antibiotics for SMA [32]. A higher percentage of medical students gave either multiple answers or the brand and price of the antibiotics as their main consideration compared to non-medical students, who were more concerned about the type or an adverse reaction from the antibiotics [32].

[32] also found out that practices regarding the use of antibiotics during SMA, very few participants "always" change the dosage or switch antibiotics during SMA were $8.1 \%$, though quite a number "sometimes" did were $41.3 \%$. The majority that did not fully understand the instruction on the antibiotic package were $60.2 \%$, and somewhat concerned about taking counterfeit antibiotics were $46.4 \%$, the respondents that did not experience any adverse effects during SMA were $71.3 \%$, those that thought that SMA was an acceptable practice were $61.3 \%$ and those that were not sure whether they could successfully treat the infection on their own were $64.3 \%$. Less than half of the participants had taken the same antibiotics with different names during a course of antibiotics $(40.1 \%)$.

[32] did a comparison between medical and non-medical students regarding the use of antibiotics with SMA showed a significant difference for understanding the instruction on the antibiotics package, whereas as expected, a higher percentage of medical students understood the instruction fully $(p=0.015)$. In addition, a higher percentage of medical students switched antibiotics during SMA
( $p=0.004)$ and did not think that they could successfully treat themselves $(p=0.011)$. A higher percentage of non-medical students were more concerned about taking counterfeit antibiotics $(p=0.011)$ and thinking that SMA is a good or acceptable practice $(p=0.002)$ [32].

A study conducted by [31] found out that prescription of antibiotics for use by a clinician, nurse, or pharmacist were $33.5 \%, 29 \%$, and $25 \%$, respectively, among undergraduate students and were 57\%, 20.4\%, and $15.5 \%$ among the community members. It was discovered that antibiotics purchases mostly took place at patent medicine stores (40\%) among the undergraduate students, unlike the community members whose main source of Purchase was at a local chemist or pharmacy (48.4\%). However, a substantial number of the undergraduate students compared to community members reported that they patronized local drug hawkers (22.7\% and 9.4\%, respectively). Regarding compliance with the prescribed duration of use of the antibiotics indicated that $85 \%$ of undergraduate students and $84 \%$ of community members completed the course of antibiotic prescription. Similarly, the majority of the respondents $(72.5 \%$ undergraduate students and $60.4 \%$ community members) suggested that antibiotic use was devoid of any side effects. In contrast, respondents reported different levels of satisfaction from the use of antibiotics. Undergraduate students mostly rated antibiotic use as good (43\%), while the community members mostly rated it as satisfactory $(40 \%)$ in resolving illnesses. The chi-square tests indicate a significant association between frequency of antibiotic use, prescribing personnel, place of Purchase, and efficacy of antibiotics in resolving illnesses with self-medication with antibiotics among the undergraduate students and community residents ( $p$-value < 0.001) [31].

In the research conducted by [33] found out that the pharmacists observed that most customers knew exactly the name and dosage of the antibiotics (how many milligrams, e.g. If 
$250 \mathrm{mg}$ or $500 \mathrm{mg}$ ), and occasionally, they referred to the name of the laboratory of origin of the antibiotics if a German, Portuguese or Indian-made antibiotics. [34].

[34] discovered that pharmacists agree SMA is an individual practice, they were of the opinion that the doctors and/or qualified health professionals were also to blame for the widespread abuse of the use of antibiotics since they are quick to prescribe for symptoms or health problems that do not necessarily require antibiotics treatment.

Moreover, pharmacists believed doctors' prescribing practices contributed to SMA since they frequently prescribe the same antibiotic for different conditions, and patients learn to recognize those antibiotics. This, according to pharmacists, led patients to overuse and didn't feel the need to seek medical help since patients who can afford to pay go straight to the pharmacy. [34]

The study also highlighted that both customers and pharmacists mentioned the practice of sharing antibiotics with family, friends, and/other people from the social network are common. Such behavior was, according to the pharmacists, influenced by the behavior of not finishing the complete course of treatment and/or stopping medications when symptoms disappear. This attitude led patients to do home storage of left-over antibiotics that are later used either for the same patient or others within the social network or family. Participants from FGD, customers, and a pharmacist agreed and explained [34]. From the study, pharmacists admitted with concern that some customers used old prescriptions to purchase antibiotics.

According to the pharmacists, it is also becoming common for customers to come with an old prescription as a picture saved in their smartphone or even shared by someone else. Normally old patients, people above 60 years old, use a lot of old prescriptions. People also got information from the internet without Doctor's prescription. [34].

\section{Methodology}

\section{Study Design}

A descriptive cross-sectional study was carried out to assess the knowledge, use, frequency, and reasons of self-medication with antibiotics among patients at Gbagada General Hospital Gbagada from February $14^{\text {th }}-19^{\text {th }}$, 2021. Gbagada General Hospital is the largest tertiary care hospital run by the government. It is one of the major suppliers of free-of-cost healthcare for the community of Gbagada for patients who cannot afford to pay for their treatment. Four hundred people were recruited from the Outpatient Department (OPD) of the hospital. This study was approved by the review board of Lagos state health service commission and Lagos University Teaching Hospital Health Research Committee.

\section{Study Area}

This study was be conducted in Kosofe Local Government Area in Lagos State, Nigeria. Kosofe means "nothing is free". This underscores the diverse commercial activities which characterized the indigenes and early settlers of the area in the mid-nineteenth century, the people were noted for massive trade in vegetables, fruits, maize, cassava, and fish. Its location at the gateway to the metropolitan Lagos further entrenches Kosofe as an important name in commerce in modernday Nigeria [35].

Kosofe is located at the Northern part of Lagos State. It is bounded by (3) other Local Governments, namely: Ikeja, Ikorodu, and Somolu. It also shares a boundary with Ogun State. Its jurisdiction comprises of seven wards and encompasses an area of about $17.85 \mathrm{sq} / \mathrm{km}$. Its headquarters is at Ogudu Road, Ojota, Lagos; presently, Kosofe falls under the East Senatorial District [35].

Self-medication with antibiotics occurs everywhere in the world, including Kosefe Local government. Where our research was conducted (General Hospital Gbagada) was a 
good place to study and capture the knowledge and use of self-medication with antibiotics.

\section{Study population}

The population comprised of all the residents in Kosofe LGA, and study subjects were out patients that use General Hospital. This comprised of those that use self-medication with antibiotics, as well as track the adverse effects in the patients that used self-medication with antibiotics.

\section{Inclusion Criteria}

Outpatient Department (OPD) of Gbagada General Hospital Gbagada Lagos. The definition of self-medication was set as the use of any antibiotics within the last 12 months, without the prescription of a doctor. This time limit of 12 months was set to eliminate the possible recall bias among the participants. Antibiotics are the medications consumed to treat bacterial and protozoal infections and that are depicted on the World Health Organization's (WHO) model list of necessary medicines [36] [37]

\section{Exclusion Criteria}

Outpatient Department (OPD) that do not use General Hospital.

\section{Sample Size Determination}

The Cochran formula is [38] - The sample size was determined in order to have $95 \%$ confidence limits of $5 \%$ maximum error of the estimate when the probability is $46 \%$ [30]. This leads to a requirement of 402 residents. For a non-response expectation, the sample size was increased to 402 Outpatient Department (OPD) of the hospital. 402 Outpatients of the Gbagada General Hospital Gbagada city area of Lagos will be recruited for the study in the aforementioned time period through probability sampling.

\section{Sampling Technique}

The technique of multi-stage sampling was used to obtain cross-sectional data for this study in Lagos state. The Lagos state was divided geographically into 37 Local governments Area.

Stage 1: The balloting method of simple random sampling was used to select a government hospital (Gbagada general Hospital) from the list of hospitals in the Local governments of Lagos state, Nigeria. Therefore, the sample sizes of 402 outpatients were distributed according to the number of patients that use a government hospital.

Stage 2: Simple random sampling method using outpatient registers was used to select the patients that would be sampled in the hospital.

Stage 3: All outpatients using selfmedication with antibiotics in the hospitals were sampled in the hospital picked.

\section{Method of Data Collection}

Informed consent was obtained from every participant, both verbal and written. Questionnaire was developed for this study based on the previous research questions related to knowledge and use of self-medication with antibiotics. A pretest was carried out for 20 outpatients of Gbagada General Hospital, and necessary modifications were carried out. Participants were given the option of answering the questionnaire themselves or having the researcher fill it based on verbal responses. The questionnaire contained five sections. The first is the demographic section, which contained questions regarding age, gender, marital status, education level, household income, occupation, and health insurance. Section B assessed the different antibiotics that the participants bought for self-administration. Section $\mathrm{C}$ gauged the reasons for self-medication and its frequency, the location for obtaining medicines, and the people they approached for advice. Section D determined the knowledge of adverse effects caused by antibiotics. Section E asked about the knowledge of inadequate use of antibiotics on antibiotic resistance. The investigator explained the study to the participants, including the conditions for participating, as well as privacy 
and confidentiality for data collection. Although the study was free from any serious ethical issues, the researcher designed a participant's information sheet that explained the voluntary nature of the study in details, and the anonymity and confidentiality in the study. Necessary translation of the contents of the tools for this research was done to assist the less-learned but with care not to influence or distort the judgment of the participants. The researcher, through trained health workers for data collection, gave the participant's information sheet and questionnaire to eligible and willing participants at the various places designated for data collection.

\section{Ethical Considerations}

Ethical approval was obtained from the Research and Ethics Committee of Lagos University Teaching Hospital. Permission was also obtained and the Chairman of Lagos State Health service commission before the commencement of the study. Participation was voluntary; all the participants were required to provide written informed consent, and they were assured of the confidentiality regarding information collected from them.

Section A was the demographic section, which will contain questions regarding age, gender, marital status, education level, household income, occupation, and health insurance. Section B assessed the different antibiotics that the participants bought for selfadministration. Section $C$ was gauged the reasons for self-medication and its frequency, the location for obtaining medicines, and the people they approached for advice. Section D was determined the knowledge of adverse effects caused by antibiotics. Section E asked about the knowledge of inadequate use of antibiotics on antibiotic resistance. Each participant was asked at the start of the questionnaire whether they self-medicated. Those who did were required to fill the whole questionnaire while the rest only filled sections $\mathrm{A}, \mathrm{D}$ and $\mathrm{E}$. The questionnaire was compiled from the already validated versions used by [37, $39,40]$ in their studies.

\section{Results}

This section presents the major findings from the study. The results are divided into five subsections, namely: Socio-demographic characteristics of respondents, The different antibiotics that the participants bought for selfadministration, The reasons for self-medication and its frequency, the location for obtaining medicines, and the people they approached for advice and the knowledge of adverse effects caused by antibiotics.

\section{Section A: Socio-Demographic Data}

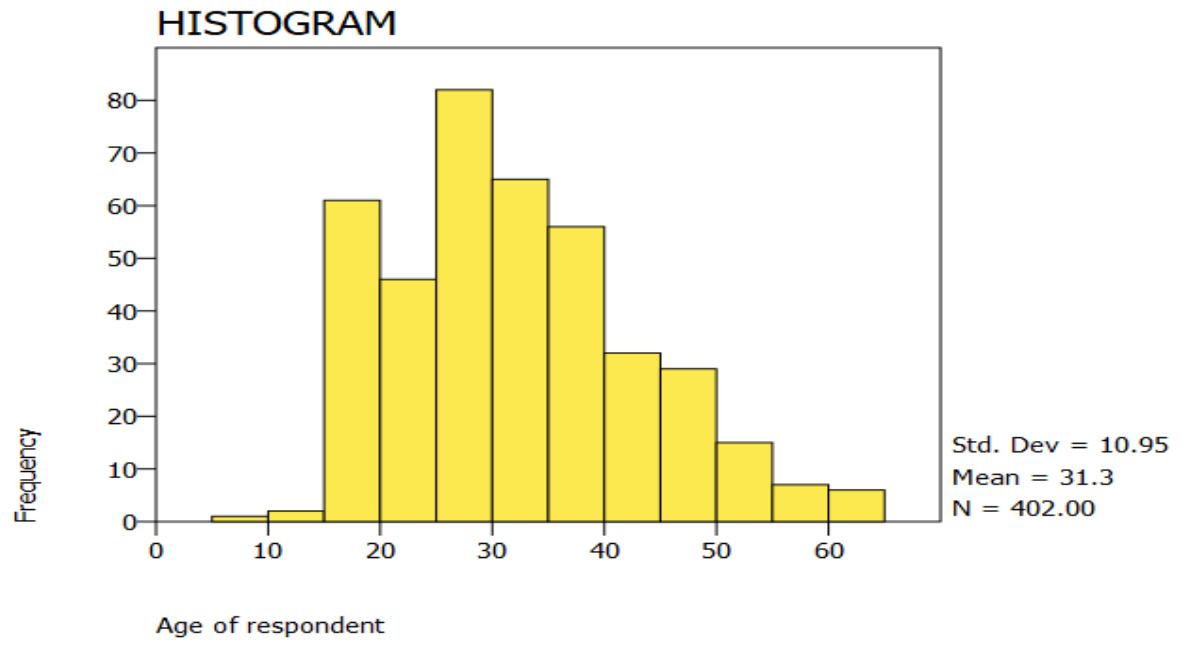

Figure 1. Socio-Demographic Data 
The mean, modal ages, and standard deviation of respondents, were 31.29 years, 30 years old, and 10.95. The youngest respondent was 8 years old, and the oldest respondent was 64.

Table 1. Socio-demographic Characteristics of Respondents

\begin{tabular}{|c|c|c|}
\hline Respondents & Frequency $n=402$ & Percentage $(\%)$ \\
\hline \multicolumn{3}{|c|}{ Have you ever taken antibiotics? } \\
\hline Yes & 381 & 94.78 \\
\hline No & 21 & 5.22 \\
\hline \multicolumn{3}{|c|}{ Have you treated yourself (self-medicated) with antibiotics } \\
\hline Yes & 289 & 71.89 \\
\hline No & 113 & 5.22 \\
\hline \multicolumn{3}{|c|}{ Sex of respondent } \\
\hline Male & 155 & 38.56 \\
\hline Female & 247 & 61.44 \\
\hline \multicolumn{3}{|l|}{ Marital Status } \\
\hline Single & 204 & 50.75 \\
\hline Married & 180 & 44.78 \\
\hline Divorced & 9 & 2.24 \\
\hline Separated & 9 & 2.24 \\
\hline \multicolumn{3}{|l|}{ Education } \\
\hline $\begin{array}{l}\text { No formal } \\
\text { education }\end{array}$ & 2 & 0.50 \\
\hline Primary & 5 & 1.24 \\
\hline Secondary & 129 & 32.09 \\
\hline Tertiary & 266 & 66.17 \\
\hline \multicolumn{3}{|l|}{ Religion } \\
\hline Christian & 307 & 76.37 \\
\hline Islam & 95 & 23.63 \\
\hline Others & 0 & 0.00 \\
\hline \multicolumn{3}{|c|}{ Employment Status } \\
\hline Employed & 156 & 38.81 \\
\hline Unemployed & 101 & 25.12 \\
\hline Self employed & 145 & 36.07 \\
\hline \multicolumn{3}{|l|}{ Income } \\
\hline$<50,000$ Naira & 193 & 48.01 \\
\hline $50,000-99,999$ & 72 & 17.91 \\
\hline $\begin{array}{l}100,000- \\
150,000\end{array}$ & 81 & 20.15 \\
\hline$>150,000$ & 56 & 13.93 \\
\hline \multicolumn{3}{|c|}{ Health Insurance status } \\
\hline Yes & 136 & 33.83 \\
\hline No & 266 & 66.17 \\
\hline
\end{tabular}


Respondents that are females were $61.44 \%$, and $38.56 \%$ were males. Half of our respondents were single $(50.75 \%)$ while $44.78 \%$ were married, $2.24 \%$ were divorced and separated, respectively.

The majority of parents/guardians were Christians (76.37\%), Muslims were 23.63\%. The respondents (parents/guardians) interviewed that had secondary education were $33.09 \%, 66.17 \%$ had tertiary education, while $1.24 \%$ had primary education and $0.50 \%$ had no formal education.

The majority of our respondents were employed $(38.81 \%$ ), about $36.07 \%$ of our respondents were Self - employed $25.12 \%$ of our respondents were unemployed. It was interesting to discover that $48.01 \%$ of our respondents earn below 50,000 Naira monthly, $17.91 \%$ earn between 50,000 naira, and 99,999 naira monthly, $20.15 \%$ earn between $100,000-$ 150,000 naira monthly, and $13.93 \%$ earn above 150,000 Naira monthly respectively.

The majority of respondents $(66.17 \%)$ do not have health insurance, while only $33.83 \%$ of respondents have health insurance, $94.78 \%$ of our respondents have taken antibiotics, while $5.22 \%$ have not taken antibiotics before.

The majority of our respondents (71.89\%) have self-medicated with antibiotics, while $28.11 \%$ do not self-medicate with antibiotics.

\section{Section B: The Different Antibiotics that the Participants Bought for Self- administration}

Ampicillin (53.23\%), Penicillin (51,24\%), chloroquine $(45.77 \%)$, and Amoxycillin $(40.05 \%)$ are the antibiotics our respondents used most for Self - medication.

\section{Section C: The Reasons for Self-medication and its Frequency, the Location for Obtaining Medicines and the People they Approached for Advice}

Table 2. The Reasons for Self-medication and its Frequency, the Location for Obtaining Medicines

\begin{tabular}{|l|l|l|}
\hline Reasons & Frequency $\mathbf{n = 4 0 2}$ & Percentage (\%) \\
\hline What is your frequency of antibiotics use? & 18 & 448 \\
\hline Weekly & 44 & 10.95 \\
\hline Monthly & 41 & 10.20 \\
\hline Once in two months & 48 & 11.94 \\
\hline Every 3 months & 251 & 62.44 \\
\hline Others & 170 & \multicolumn{2}{|l|}{} \\
\hline Who prescribed the antibiotics? & 51 & 42.29 \\
\hline Doctor & 139 & 12.69 \\
\hline Nurse & 42 & 34.58 \\
\hline Pharmacist & 10.45 \\
\hline Others & 186 & \multicolumn{2}{|l|}{} \\
\hline Place of antibiotics purchase & 168 & 46.27 \\
\hline Local Chemist & 4 & 41.79 \\
\hline Patent Medicine store & 44 & 1.00 \\
\hline Local drug hawkers & \multicolumn{2}{|l|}{} \\
\hline Others & \multicolumn{2}{|l|}{} \\
\hline Did you comply with the duration of use of antibiotics? & 79.95 \\
\hline Yes & 319 & 20.65 \\
\hline No & 83 & 36.07 \\
\hline Were there any side effects? & 145 \\
\hline Yes & \multicolumn{2}{|l|}{} \\
\hline
\end{tabular}




\begin{tabular}{|l|l|l|}
\hline No & 257 & 63.93 \\
\hline Was the antibiotics effective in resolving the illness? & 39.30 \\
\hline Excellent & 158 & 43.53 \\
\hline Satisfactory & 175 & 15.17 \\
\hline Good & 61 & 1.99 \\
\hline No results & 8 & 72.64 \\
\hline How much did you understand the instructions? & 24.88 \\
\hline Fully understood & 292 & 2.49 \\
\hline Partly understood & 100 & \\
\hline Did not understand at all & 10 & 33.08 \\
\hline $\begin{array}{l}\text { Have you ever found out that you had taken the same antibiotics with different } \\
\text { names at the same time? }\end{array}$ & 66.92 \\
\hline Yes & 133 & 22.64 \\
\hline No & 269 & 77.36 \\
\hline $\begin{array}{l}\text { Have you ever had adverse reaction when you took antibiotics for Self - } \\
\text { medication? }\end{array}$ & 91 \\
\hline Yes & 311 \\
\hline No &
\end{tabular}

For frequency of antibiotics use majority of our respondents fall in the category of others (62.44\%). Doctor's and Pharmacist prescription for our respondents was $42.29 \%$ and $34.58 \%$, respectively. It is worthy to note that some patient calls their health care providers on the phone or use telemedicine which has come to stay.

The place of Purchase of antibiotics our respondents use for Self - medication were Local chemist (46.27\%) and Patent Medicine stores $(41.79 \%)$. It was amazing that $79.35 \%$ of our respondents complied with the duration of the use of the antibiotics, which is good, and $63.93 \%$ of our respondents reported that they had no side effects while $36.07 \%$ had side effects.

Surprisingly, $98.01 \%$ of our respondents stated that the antibiotics was effective to resolving their illness. Our respondents indicated that $36.07 \%$ and $25.87 \%$ have taken antibiotics once and twice, respectively, between March 2020 and February 2021, which was during the COVID - 19 First and second wave in Nigeria. It is worthy to note $11.69 \%$ didn't take antibiotics in the last one year, and an 8-years-old child took antibiotics 24 times within one year because of a medical history of infection in the leg. (Bone joint).

Long delays in hospital (43.03\%), Convenience (26.37\%), Cost saving (20.90\%), and attitude of hospital staff (18.16\%) were mostly the reasons our respondents were selfmedicating with antibiotics. Our respondents self-medicated with antibiotics for Infection (40.55\%), Fever (38.31\%), Sore throat (27.36\%), Cough (26.62\%), Malaria (26.12\%), Typhoid (19.40\%), Diarrhea (16.92\%), Aches and pains (16.67\%).

Respondent's selections of antibiotics were based on Recommendation by a Doctor (41.29\%), Based on my own experience and knowledge of antibiotics (30.85\%), recommendation by community Pharmacist (28.36\%), Previous Doctor's prescription $(23.13 \%)$, and recommendation by Nurse (16.42\%). Our respondents that Fully understood the instruction of the antibiotics they used to self-medicate were $72.64 \%$.

The majority of our respondents $(77.11 \%)$ took only one type of antibiotics when they were ill, $19.25 \%$ took two types of antibiotics, while $2.99 \%$ took three types of antibiotics, and only 0.25 took four types of antibiotics. 
Our respondents that found out that they had taken the same antibiotics with different names at the same time were $33.08 \%$.

Our respondents stopped taking antibiotics after completion of the course (35.82\%), a few days after recovery (30.85\%), After symptoms disappeared $(29.60 \%$ ), while $9.45 \%$ stopped after antibiotics finished/ran out, $7.46 \%$ stopped after a few days regardless of the outcome. Our respondents that had an adverse reaction when they self-medicate with antibiotics were $22.64 \%$, and $11.94 \%$ stopped taking antibiotics when they experienced an adverse reaction, while $9.20 \%$ and $4.98 \%$ consulted a Doctor and Pharmacy staff, respectively.

\section{Section D: The Knowledge of Adverse Effects Caused by Antibiotics and Section E: The Knowledge of Inadequate use of Antibiotics on Antibiotic Resistance}

Table 3. The Knowledge of Adverse Effects Caused by Antibiotics and the Knowledge of Inadequate use of Antibiotics on Antibiotic Resistance

\begin{tabular}{|c|c|c|}
\hline Section D: & Frequency $n=402$ & Percentage $(\%)$ \\
\hline \multicolumn{3}{|c|}{ Do you know what antibiotics are? } \\
\hline Yes & 360 & 89.55 \\
\hline No & 42 & 10.45 \\
\hline \multicolumn{3}{|c|}{ Antibiotics can cure all infections } \\
\hline True & 132 & 32.59 \\
\hline False & 271 & 67.41 \\
\hline \multicolumn{3}{|c|}{ Antibiotics might be effective even if I don't complete my dosage } \\
\hline Yes & 194 & 48.26 \\
\hline No & 208 & 51.74 \\
\hline \multicolumn{3}{|c|}{ Level of awareness of antibiotics resistance } \\
\hline Low & 79 & 19.65 \\
\hline Moderate & 257 & 63.93 \\
\hline High & 66 & 16.42 \\
\hline \multicolumn{3}{|c|}{$\begin{array}{l}\text { Do you use left-over antibiotics from friends and family members without } \\
\text { Doctor's prescription? }\end{array}$} \\
\hline Always & 13 & 3.23 \\
\hline Sometimes & 147 & 36.57 \\
\hline Never & 242 & 60.20 \\
\hline \multicolumn{3}{|l|}{ Section E: } \\
\hline \multicolumn{3}{|c|}{ Do you use another family members antibiotics? } \\
\hline Always & 17 & 4.23 \\
\hline Sometimes & 127 & 31.59 \\
\hline Never & 258 & 64.18 \\
\hline \multicolumn{3}{|c|}{ Unnecessary use of antibiotics makes them ineffective } \\
\hline True & 277 & 68.91 \\
\hline False & 125 & 31.09 \\
\hline \multicolumn{3}{|c|}{ Have you heard of resistance to antibiotics? } \\
\hline Yes & 205 & 51.00 \\
\hline No & 197 & 49.00 \\
\hline
\end{tabular}

Respondents knew what antibiotics are were $89.55 \%$ while $32.59 \%$ of our respondents said antibiotics can cure all infections, and $48.26 \%$ of our respondents said antibiotics might be 
effective even if they don't complete their dosage. Level of awareness of antibiotic resistance amongst our respondents for were moderate $(66.93 \%)$, Low (19.65\%), and High (16.42\%).

Respondents that use left-over antibiotics from friends and family members without Doctor's prescription sometimes and always were $36.57 \%$ and $3.23 \%$, respectively.

The common adverse reaction of antibiotics experienced by respondents were Nausea (26.87\%), Rash (24.13\%), Vomiting (13.68\%), Drug resistance (12.19, Diarrhea (11.19\%), and Vaginal thrush 93.235).

Our respondents said that Intravenous is better than oral medication (27.36\%), Higher doses result in faster recovery (15.67\%), Lower doses result in less adverse reactions (17.91\%), Switching antibiotics enhances drug effects (17.66\%), Broad-spectrum antibiotics are better than narrow-spectrum ones (25.12\%) and Switching antibiotics reduces adverse reactions (14.93\%). $64.18 \%$ of our respondents have never used another family member's antibiotics. 68.91 of our respondents agree that the unnecessary use of antibiotics makes them ineffective. $51 \%$ of our respondents have heard of resistance to antibiotics.

Respondents knew that resistance to antibiotics can be caused by Not completing the dosage $(49.25 \%)$, Using antibiotics repeatedly (43.28\%), and Self - medication (34.08\%). Respondents knew that antibiotics is used for treating Bacteria infection (85.32\%), viral infection (17.66\%), and others (8.21\%).

\section{Discussion}

Between March 2020 and February 2021, which was during the COVID - 19 First and second wave in Nigeria, $36.07 \%$ and $25.87 \%$ of outpatients of Gbagada General Hospital took antibiotics once and twice, respectively. Long delays in hospital $(43.03 \%$, Convenience (26.37\%), Cost saving (20.90\%), and attitude of hospital staff $(18.16 \%)$ were mostly the reasons our respondents were self-medicating with antibiotics. This is similar to the discovery of [31], those reasons reported for engaging in self-medication among undergraduate students and community members were due to long delays in the hospital, it being cheaper not to go to the hospital, and the distance to the hospital" [31]. Respondents self-medicated with antibiotics for Infection (40.55\%), Fever (38.31\%), Sore throat (27.36\%), Cough (26.62\%), Malaria (26.12\%), Typhoid $(19.40 \%)$, Diarrhea (16.92\%), Aches and pains $(16.67 \%)$. The majority of respondents (66.17\%) do not have health insurance, while only $33.83 \%$ of respondents have health insurance. Level of awareness of antibiotic resistance amongst our respondents for were moderate $(66.93 \%)$, Low (19.65\% and Hight $(16.42 \%)$. This justifies $[31,32]$ findings stating that" the most common reasons for selfadministration of antibiotics were sore throat, fever, running nose and cough [31] [32]. Other reasons were dental infection, rheumatism, and fatigue, nasal congestion, fever, aches and pains, vomiting, diarrhea, and skin wounds.

Respondents that had tertiary education were $66.17 \%$, Chi-Square showed that there was a significant association between level of education and use of antibiotics. Level of education had an effect in the level of knowledge and use of Self - medication with antibiotics. $25.12 \%$ of our respondents were unemployed, and the majority of respondents (66.17\%) do not have health insurance righting to an increase in self-medication with antibiotics. As discovered by [31] that being unemployed and having no health insurance resulted to the self-administration of antibiotics. Most elderly outpatients at Gbagada General hospital do not self-medicate with antibiotics, unlike the young adult outpatients of Gbagada General hospital Gbagada. According to similar research conducted earlier, the most common self-medicating group were adults aged 40-49 while the least self-usage was in the 60-69 age groups, unlike a study carried out by [33] that discovered old patients, people above 60 years 
old use a lot of old prescriptions for selfmedication with antibiotics. People also get information form the internet without Doctor's prescription [34].

Doctor's and Pharmacist prescriptions for our respondents were $42.29 \%$ and $34.58 \%$, respectively. For frequency of antibiotics use, the majority of our respondents fall in the category of others $(62.44 \%)$, meaning that they only use antibiotics when needed and not weekly, monthly, bimonthly, or once in 3 months. The place of Purchase of antibiotics our respondents use for Self - medication were Local chemists (46.27\%) and Patent Medicine stores $(41.79 \%)$. $32.59 \%$ of our respondents said antibiotics can cure all infections. $48.26 \%$ of our respondents said antibiotics might be effective even if they don't complete their dosage. $36.57 \%$ and $3.23 \%$ of our respondents use left-over antibiotics from friends and family members without Doctor's prescription sometimes and always, respectively. The common adverse reaction of antibiotics experienced by respondents were Nausea (26.87\%), Rash (24.13\%), Vomiting (13.68\%), Drug resistance (12.19\%), Diarrhea (11.19\%), and Vaginal thrush 93.235). $64.18 \%$ of our respondents have never used another family member's antibiotics. 68.91 of our respondents agree that the unnecessary use of antibiotics makes them ineffective. This is similar to a survey conducted by [31] those undergraduate students who showed that suggestions from family and friends (34.3\%) were the most common explanation for self-medication of self-diagnosed illnesses. While in the community, prescription by physicians $(33.5 \%)$ were the highest response for choice of antibiotics, followed by previous experience with the antibiotic (18\%) and knowledge of the antibiotic $(11 \%)$ [31]. The researchers discovered that undergraduate students were more likely than the community residents to subscribe to using left-over antibiotics from friends or family members without doctor's prescription; most times $(12.5 \%$ and $8.5 \%$, respectively) and sometimes $(57.4 \%$ and $40.3 \%$ ) [31]. Similarly, the undergraduate students were more likely than the community residents to use antibiotics based on relative's advice; always ( $25.4 \%$ and $18.3 \%$, respectively) and sometimes (61.4\% and 37.7\%) [31].

Knowledge of ABR varied among the respondents. Our respondents said that Intravenous is better than oral medication (27.36\%), Higher doses result in faster recovery (15.67\%), Lower doses result in less adverse reactions $(17.91 \%)$, Switching antibiotics enhances drug effects (17.66\%), Broadspectrum antibiotics are better than narrowspectrum ones (25.12\%) and Switching antibiotics reduces adverse reactions (14.93\%). Respondents knew that resistance to antibiotics can be caused by Not completing the dosage (49.25\%), Using antibiotics repeatedly (43.28\%), and Self - medication (34.08\%). Respondents knew that antibiotics is used for treating Bacteria infection (85.32\%), viral infection $(17.66 \%)$, and others $(8.21 \%)$. This justifies [31] findings that the undergraduate students, compared to the community residents displayed more knowledge of the fact that antibiotics cannot cure all infections (53\% and $42.4 \%$ ), that antibiotics are not used for cold (57.5\% and $55.3 \%$ ), and that unnecessary use of antibiotics could make them ineffective $(68.4 \%$ and $62.9 \%$ ) In contrast, community residents displayed better knowledge compared to undergraduate students when asked if antibiotics can be used for body pains $(59.1 \%$ and $37.2 \%$ ) and if antibiotics might be effective without completing the dosage $(52.9 \%$ and $43.9 \%$ ); the correct response was false. The undergraduate students, compared to the community residents, displayed less knowledge of the fact that self-medication could lead to the development of Antibiotics resistance (32.6\% and $42.2 \%$, respectively), but undergraduate students showed more knowledge that indiscriminate antibiotic use could cause Antibiotics resistance (51.3\% and 41.8\%) [31]. 
We are therefore accepting our hypothesis that lack of knowledge of awareness of antibiotics resistance $\mathrm{p}=0.024$ and high cost gives rise to Self - medication with antibiotics and there are other multiple factors or significant determinants like COVID-19 lockdown restrictions, long delays in hospital, the attitude of hospital staff and lack of health insurance determine causes of Self medication with antibiotics.

\section{Conclusion}

The emergence and spread of drug-resistant pathogens have acquired new resistance mechanisms, which has led to antimicrobial resistance and has continued to threaten our ability to treat common infections. The most alarming is the rapid global trend of multi- and pan-resistant bacteria (also known as "superbugs") that cause infections that are not treatable with existing antimicrobial medicines such as antibiotics [1].

In 2019 WHO discovered 32 antibiotics in clinical development that address the WHO list of priority pathogens, six were classified as innovative. A major concern was the lack of access to quality antimicrobials. Antibiotic shortages are currently affecting countries of all levels of development and especially in healthcare systems [1].

Antibiotics are becoming increasingly ineffective as drug resistance increases globally, making it more difficult to treat infections and death. New antibacterial are really vital - for example, to treat carbapenem-resistant gramnegative bacterial infections as identified in the WHO priority pathogen list [1]. The outpatients of Gbagada General Hospital who are using these antibiotics generally do not have full information regarding their proper use. However, if the outpatients of Gbagada General Hospital do not stop self-medication with antibiotics now, these new antibiotics will suffer the same fate as the current ones and become ineffective.

\section{Recommendation}

a) There is pressing importance for public health agencies, professionals, and the Federal Ministry of Health in Nigeria to enforce existing laws on antibiotics sales by Pharmacies, drug hawkers and enlighten the people on the dangers of ABR.

b) We recommend the use of media (television, radio, newspaper, magazine, billboards, Facebook, Twitter, Instagram, Linkedin, Telegram, Tik Tok, Whatsapp etc.) to discourage the masses from selfmedication with antibiotics.

c) The Public should be encouraged to stop the misused and overuse of antimicrobials.

d) The Public should ensure that they drink clean water and practice proper sanitation and adequate infection prevention and control to mitigate the spread of microbes.

\section{Acknowledgement}

All praises to God for the gift of life, mercy, and good health that enabled me to complete this research. My sincere gratitude to Lagos State Health Service Commission and Gbagada General Hospital for the permission, support, and opportunity given to me to carry out this study.

I would like to express my gratitude to Dr. Ann Ogbenna (a senior lecturer at College of the Medicine University of Lagos), who was instrumental to getting ethical approval for this research, data collector, Oluwatosin Adewumi, Mentor, Ms. Jesna, my lecturers, and its Management of Texila American University. I am highly thankful for the kind support bestowed on me by my Husband Mr. Noris Chimezie Odis, children (Chimuanya, Ogechukwu, Chisimudi), Sweet Mum, Mrs. Bibiana Anyichie, Siblings, family, friends, and all respondents in this study.

\section{Conflicts of Interest}

The author declares no conflict of interest. 


\section{References}

[1] World Health Organization, 2020, Antimicrobial resistance, https://www.who.int/news-room/factsheets/detail/antimicrobial-resistance.

[2] Hamel MJ, Odhacha A, Roberts JM, Deming MS. Malaria control in Bungoma District, Kenya: a survey of home treatment of children with fever, bed net use and attendance at antenatal clinics. Bull World Health Organ 2001;79(11):1014-1023 [PMC free article] [PubMed] [Google Scholar].

[3] Behrman RE, Kliegman RM, Jenson HB. Nelson Essentials Textbook of pediatrics third edition W.B. Saunders company Philidelphia. 2000. [Google Scholar].

[4] Hernandez-Juyol M, Job-Quesada JR., 2002 Dentistry, and self-medication: a current challenge. Med Oral, 7(5):344-47.

[5] Kiyingi KS, Lauwo JA., 1993 Drugs in the home: danger and waste. World Health Forum, 14(4):381-84

[6] Napolitano F, Izzo MT, Di Giuseppe G, Angelillo IF. 2013, Public knowledge, attitudes, and experience regarding the use of antibiotics in Italy. PLoS One, 8(12): e84177.

[7] Grigoryan L， Burgerhof JG， Degener JE, Deschepper R, Lundborg CS, Monnet DL, et al., 2008, Self-Medication with Antibiotics and Resistance (SAR) Consortium. Determinants of selfmedication with antibiotics in Europe: the impact of beliefs, country wealth and the healthcare system. $J$ Antimicrob Chemother, 61:1172-79.

[8] Drug Utilization Research Group, 1996, Latin America WHO. Multicenter study on selfmedication and self-prescription in six Latin American Countries. Clin Pharmacol Ther. 61:48893.

[9] Kafle KK, Gartoulla RP., 1993, Self-Medication and its Impact on Essential Drugs Schemes in Nepal: A Socio-Cultural Research Project: Action Programme on Essential Drugs. Geneva: World Health Organization.

[10] Mumtaz Y, Jahangeer SA, Mujtaba T, Zafar S, Adnan S., 2011, Self-medication among university students of Karachi. JLUMHS, 10(03):102-05.
[11]Ali SM, Fatima M, Ali L, 2015, SelfMedication among Downtown Urban Population of Karachi, Pakistan. Indian Journal of Medical Research and Pharmaceutical Sciences, 2(4).

[12] Phalke VD, Phalke DB, Durgawale PM., 2006, Self-medication practices in rural Maharashtra. Indian J Community Med, 31:34-35.

[13]WHO, 1998, World Health Organization: The role of the pharmacist in self-care and selfmedication. In Report of the 4th WHO Consultative Group on the Role of the Pharmacist in Health Care System. Geneva.

[14]Laporte JR, Castel JM., 1992, [The physician and self-medication]. Med Clin (Barc), 99(11):41416.

[15] Stratchounski LS, Andreeva IV, Ratchina SA, Galkin DV, Petrotchenkova NA, Demin AA, et al., 2003, The inventory of antibiotics in Russian home medicine cabinets. Clin Infect Dis. 37(4):498-505.

[16] Okumura J, Wakai S, Umenai T., 2002, Drug utilization and self-medication in rural communities in Vietnam. Soc Sci Med, 54(12):1875-86.

[17] Calva J, Bojalil R., 1996, Antibiotic use in a periurban community in Mexico: a household and drugstore survey. Soc Sci Med., 42(8):1121-28.

[18]Lansang MA, Lucas-Aquino R, Tupasi TE, Mina VS, Salazar LS, Juban N, et al., 1990, Purchase of antibiotics without prescription in Manila, the Philippines. Inappropriate choices and doses. J Clin Epidemiol, 43(1):61-7.

[19] Crigger NJ, Holcomb L, Grogan RL, Vasquez M, Parchment C, Almendares J, et al., 2004, Development of the choices and acquisition of antibiotics model from a descriptive study of a lay Honduran population. Int J Nurs Stud., 41(7):74553.

[20] Arul Prakasam K, Senthil NK, Ramesh J., 2011, Students' knowledge of antibiotics: a cross-sectional study of students in Tamil Nadu. Int J Pharm Pharm Sci., 3(1).

[21]Balbuena FR, Aranda AB, Figueras A., 2009, Self-medication in older urban Mexicans: an observational, descriptive, cross-sectional study. Drugs Aging, 26(1):51-60.

[22]Chan G, Tang S., 2006, Parental knowledge, attitudes and antibiotic use for acute upper 
respiratory tract infection in children attending a primary healthcare clinic in Malaysia. Singapore Med J., 47(4):266-70.

[23] Brown S, Warnnissorn T, Biddle J, Panikabutra K, Traisupa A., 1982, Antimicrobial resistance of Neisseria gonorrhoea in Bangkok: is single-drug treatment passe. Lancet., 2(8312):1366-68.

[24] Appelbaum PC, Bhamjee A, Scragg JN, Hallett AF, Bowen AJ, Cooper RC., 1977, Streptococcus pneumonia resistant to penicillin and chloramphenicol. Lancet., ii:995-97.

[25]Farrar WE, Eidson M., 1971, R factors in strains of Shigella dysenteriae type 1 isolated in the western hemisphere during 1969-1970. J Infect Dis., 124(3):327-29.

[26] Olarte J, Galindo E., 1973, Salmonella typhi resistant to chloramphenicol, ampicillin, and other antimicrobial agents: strains isolated during an extensive typhoid fever epidemic in Mexico. Antimicrob Agents Chemother, 4(6):597-601.

[27] Sturm AW, van der Pol R, Smits AJ, van Hellemondt FM, Mouton SW, Jamil B, et al., 1997, Over-the-counter availability of antimicrobial agents, self-medication and patterns of resistance in Karachi, Pakistan. J Antimicrob Chemother, 39(4):543-47.

[28] Butt ZA, Gilani AH, Nanan D, Sheikh AL, White F., 2005, Quality of pharmacies in Pakistan: a cross-sectional survey. Int $J$ Qual Health Care, 17(4):307-13.

[29] Qidwai W, Krishanani MK, Hashmi S, Afridi M, Ali RA, et al., 2006, Private drug seller's education in improving prescribing practices. $J$ Coll Physicians Surg Pak., 16:743-46.

[30] Rabbani F, Cheema FH, Talati N, Siddiqui S, Syed S, Bashir S, et al., 2001, Behind the counter: pharmacies and dispensing patterns of pharmacy attendants in Karachi. J Pak Med Assoc., 51:149-54. https://www.ncbi.nlm.nih.gov/pmc/articles/PMC602 $3284 /$.

[31] Ajibola, O., Omisakin, O. A., Eze, A. A., \& Omoleke, S. A. (2018). Self-Medication with Antibiotics, Attitude, and Knowledge of Antibiotic Resistance among Community Residents and Undergraduate Students in Northwest Nigeria.
Diseases (Basel, Switzerland), 6(2), 32. https://doi.org/10.3390/diseases6020032.

[32] Haque M, Rahman NAA, McKimm J, Kibria GM, Azim Majumder MA, Haque SZ, Islam MZ, Binti Abdullah SL, Daher AM, Zulkifli Z, Rahman S, Kabir R, Lutfi SNNB, Aishah Binti Othman NS. Self-medication of antibiotics: investigating practice among university students at the Malaysian National Defence University. Infect Drug Resist. 2019; 12:1333-1351 https://doi.org/10.2147/IDR.S203364. [33] Torres NF, Solomon VP, Middleton LE, 2020, Identifying the commonly used antibiotics for selfmedication in urban Mozambique: a qualitative study BMJ Open 2020;10: e041323. doi: 10.1136/bmjopen-2020-041323.

[34] Torres, N.F., Solomon, V. \& Middleton, L.E. Patterns of self-medication with antibiotics in Maputo City: a qualitative study. Antimicrobe Resist $\begin{array}{llllll}\text { Infect } & \text { Control } & \mathbf{8}, & 161 & \text { (2019). }\end{array}$ https://doi.org/10.1186/s13756-019-0618-z.

[35] Kosofe Local Government Area, 2017, About Kosofe http://kosofelocalgovtarea.blogspot.com/2017/09/ab out-kosofe.html?m=1.

[36] WHO, 2013, Model List of Essential Medicines 18th list. Geneva Switzerland: WHO Press.

[37] Ramay BM, Lambour P, Ceron A., 2015, Comparing antibiotic self-medication in two socioeconomic groups in Guatemala City: a descriptive cross-sectional study. BMC Pharmacol Toxicol., 16:11.

[38] Araoye, M. O., 2003, Research methodology with statistics for health and social sciences. First edition Nathadex Publisher Ilorin Nigeria. pp 119.

[39] Shah SJ, Ahmad H, Rehan RB, Najeeb S, Mumtaz M, Jilani MH, et al., 2014, Self-medication with antibiotics among non-medical university students of Karachi: a cross-sectional study. BMC Pharmacol Toxicol., 15:74.

[40] Ilhan Mustafa N, Durukan Elif, Ilhan Sevil Ozger, Aksakal F Nur, Ozkan Seçil, Bumin Mehmet Ali, 2009, Self-medication With Antibiotics: Questionnaire Survey Among Primary Care Center Attendants, 18(12):1150-1157. doi:10.1002/pds.1829 https://pubmed.ncbi.nlm.nih.gov/19827009/. 